\title{
Mechanical View of Corrosion Phenomenon in Concrete Quadrangular of Power Transmission Lines
}

\author{
Moein Zargar ${ }^{1}$, Hossein Gholami ${ }^{2}$, Morteza Soltani ${ }^{3}$, Mohsen Ghane ${ }^{4 *}, K_{a v e h}$ Ostad-Ali- \\ Askari $^{2}$, Vijay P. Singh ${ }^{5}$ \\ ${ }^{I}$ Department of Civil Engineering, Farzanegan Institute of Higher Education, Isfahan, Iran \\ ${ }^{2}$ Department of Civil Engineering, Isfahan (Khorasgan) Branch, Islamic Azad University, Isfahan, Iran \\ ${ }^{3}$ Department of Architectural Engineering, Shahinshahr Branch, Islamic Azad University, Shahinshahr, Iran \\ ${ }^{4}$ Civil Engineering Department, South Tehran Branch, Islamic Azad University, Tehran, Iran \\ ${ }^{5}$ Department of Biological and Agricultural Engineering \& Zachry Department of Civil Engineering, Texas A \\ and M University, 321 Scoates Hall, 2117 TAMU, College Station, Texas 77843-2117, U.S.A. \\ *Corresponding Author: Mohsen Ghane, Civil Engineering Department, South Tehran Branch, Islamic \\ Azad University, Tehran, Iran
}

\begin{abstract}
The papers on corrosion at the concrete stands of power transmission lines have been considered separately for the chemical aspect of the subject and are more concerned with how the reactions and factors affecting it. In this study, the case is analyzed with completely different attitude and it is shown that what is the main reason for the beginning of crack, demolition and decomposition of concrete has a mechanical aspect and depends on behavior of structure against the forces involved and the chemical agents are affective on its further development and intensification.
\end{abstract}

Keywords: concrete; chemical aspect; structure; mechanical aspect

\section{Introduction}

One of the disadvantages of concrete and quadrangular foundations is the fracture and breakage of steel coated concrete, which leads to rusting and reversal of the base. If can be achieved due to its occurrence and affective factors in the creation of this phenomenon, it is certainly possible that with the used technical arrangements in the design can be overcome on this disadvantage in concrete foundations. In order to achieve the mechanical factors involved in the corrosion phenomenon particular attention of following instances can be helpful and affective, but the meaning of several key words in this paper is propounded before description of them (Hadian N, 1996). Fractures in covering concrete are recognized to expedite the starting of steel erosion in reinforced concrete structures. To reduce the effect of fractures on the decline of reinforced concrete structures, modern procedures in popular plan codes often restrict the concrete surface fracture width. The last researches, however, show that the concrete-reinforcement interfacial situation is a more basic standard linked to reinforcement fracture. it can examine the link between macroscopic harm at the concrete-steel joint and fracture starting of reinforcement set in simple and fiber reinforced concrete. A duty life plan is essential instrumentation for civil engineers to confirm that the structural totality and functionality of the structure is not damaged within a stated time frame, i.e. the duty existence. The available article checks a different restriction condition: erosion-induced cover rupture. Digital image correlation can use to determine corrosion-induced distortions containing contortions between steel and cementitious matrix as well as configuration and extension of erosion-induced fractures. Chloride erosion of steel reinforcement in concrete is one of the main reasons for the collapse of reinforced concrete structures.

Cantilever beams, brittleness, bond, fatigue, ductility, crack, corrosion, toughness, split, progressive (Hadian N, 1996). Frosted soil is so delicate to the temperature variation. The melt of ice in the soil can lower the stamina valence of the foundation. A three-dimensional pattern expanded to anticipate 
the thermal method of the frosted soil ground and the concrete base, examining the hydration heat of concrete. Stage variation between water and ice is examined by applying the sensitive heat capacity procedure. The consequences display that the concrete foundation built by the cast-in-place procedure has a great impact on the thermal regime of the frosted soil base in about one month after the base built. The soil nearby the foundation encounters intense melting-freezing procedure in this time. The reinforced concrete bases in a wayside court have wide reinforcing steel in metal link with the ground director. The bases may present importantly to the dispersion of the fault and leakage contemporary. Easy-to-apply calculations and figures are reported to define the ground persistence of different kinds of basis faced in substation yards. The reliability of the systematic procedure has been confirmed with scale model experiments. The land persistence of the bases, evaluated as offered in the article, can be applied to assess the role of the bases as a grounding base.

It must be considered to this simple static subject that the concrete foundations of power transmission lines are affected by wind load with the cantilever beams and the maximum resistant anchor is at the beginning of the base and linearly is reduced so that at the end of the beam and the point of loading reaches to zero and figure 1 shows the description it. (Hadian N, 1996). For the fundamental cantilevered design, the prominent edge shift was displayed to enhance with wind speed to power notably higher than two, demonstrating the wind sensiblity of these structures. big composite structures, such as composite wind may represent many collapse procedures that contend the modeling scheme and methodologies planners accord in finite element analysis. The composite beams are the main loading-carrying elements and could display various fracture procedures owing to challenging for collapse methods. Building nonlinearities related to geometry, materials, and contact are contained. information of all working situations can be gained by only test information of a few working situations by applying uniform plan procedure and regression identifications.

-breakage in the collar of the foundations (approximately 1/5 meter above the bases), in some areas such as Mazandaran after damaging the concrete, appearing rebars and to prevent the base from falling, the beginning of 2 percent of low voltage network bases are settled in the hollow metal barrels and the foundations mast hugged in the barrels and then they are filled with the concrete ${ }^{1}$ (Hadian $\mathrm{N}$, 1996). It was discovered that detriment to the reinforced concrete constructions was mostly because of non-ductile describing of the structural elements, strong-beam weak-column situation, captive-column and short-column results, soft and weak stories mechanism, nonuniformity in project and elevation, unconfined gable/infill walls, bad mechanism, and the low modality of construction substances.

-the lack of contact of the bases in crumbled area with the soil and use of drinking water to make the beam in working-places which eliminates the determinative and fundamental role of chemical agents in the corrosion phenomenon (Hadian N, 1996). signals of destruction around the bottom flange of the set chain were determined in a large number of available concrete bases. As a consequence, the placed loop practiced extreme vertical movement. A wireless structural totality monitoring method was expanded and installed in the ground to observe the resistance by quantifying the movement templates and eventually alerting any considerable motions of the embedded ring. This was attained by applying wireless movement sensors placed at the bottom of the foundation. The consequences attained from the sensors and supervisory adjust and information attainment displayed that the embedded ring showed considerable vertical movement mainly during times of stormy wind speed and during shut down and startup occurrences. The quantified movement was unstable around the environment of the base as a consequence of the wind orientation and the twister uplift powers. The extreme vertical motion was detected in the side where the twist is going around upwards. The ground experiment showed that structural totality monitoring procedure suggests considerable possible for modifying the validity and security of wind bases.

-failure to report corrosion observations in round pre-pressed bases.

-more observation of corrosion intensity in concrete quadrangular bases with double- circuit wiring condition.

\footnotetext{
${ }^{1}$ Mazandaran Low Voltage Network Database
}

International Journal of Modern Studies in Mechanical Engineering (IJMSME) 


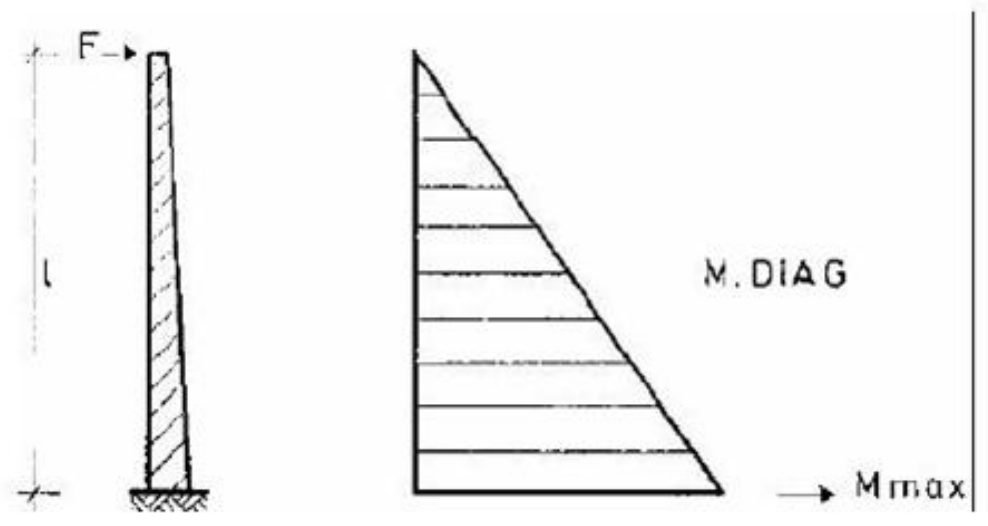

Fig1. The concrete foundations of power transmission lines are affected by wind load with the cantilever beams (Hadian N, 1996).

fractures in covering concrete are recognized to speed up the starting of steel erosion in reinforced concrete constructions. To decrease the effect of fractures on the deterioration of reinforced concrete constructions, available procedures in (inter)national plan codes often curb the concrete surface fracture width. new researches but, demonstrate that the concrete-reinforcement interfacial situation is a more fundamental standard related to reinforcement erosion. This task examines the link between the macroscopic loss at the concrete-steel joint and erosion starting of reinforcement setted in simple and fiber reinforced concrete. A detriment frame is expanded for checking the extent of fracture or detriment infiltration in a large-scale concrete element induced by the corrosion method under different boundary situations. The frame combines a huge bit creation algorithm, an expression of the detriment model and a universal optimization algorithm. The consequences display how boundary situations control detriment evolution, discovering outlines from perfection infiltration to arrest of loss at various infiltration levels within the element. In specific, it is displayed that detriment is arrested under outside pressure and fixed movement boundary situations, but quite infiltrate under stress-free boundary situation.

\subsection{Effective Factors in Development and Spreading Defeat of Concrete Structures (Hadian N, 1996)}

\section{- Ductility}

The ductility factor is a type of storage capacity and energy absorption that requires the large deformation in structure without any damage. Basically concrete structures are week in stretching and cutting and should compensate for this defect with steel. The main role of concrete is to withstand pressure. This brittle material has a great deformation. Therefore, if the stress fields in the structure are not correctly predicated or if fragility of material is not amended by using special steel making and screw driving methods the concrete structure will not formable. The loading of the wind alternately and reverse (with repetition of stretching to pressure and reverse) in the non- elastic region it will make the great changes in the resistance, anchor-curvature relation and cutting resistance of fragments. For example, when a beam reaches to non- elastic region under the positive effect of anchor the tensional steel finds non-elastic deformation and cracks occur at the cross-section of tensional region. By reversing the direction of anchor and consequently the curvature the cracks in the new compression zone will not completely closed because the steel has become permanent in stretch. If the anchor in the negative direction also crosses the beam into cracking after a complete cycle the open cracks is created in all cross-sectional height and the bend stiffness will depend on action of steel exclusively. Fig 4 shows that the reinforced concrete console beam is affected by the single -ended load and it is reached to final curvature and final anchor at its critical point (Hadian N, 1996) ${ }^{2}$. The plastic area is in the vicinity of resting-place in the longitudinal direction where the entry anchor is larger than inclined anchor and the angular circulation is more concentrated in this region. We assume that the curve of bending variation or angular circulation is ideal and divided into elastic and nonelastic regions and the plot of variation along the beam in accordance with Fig 2 in which the length (Lp) shows the non-elastic circulation region which is same plastic area (Hadian N, 1996).

\footnotetext{
${ }^{2}$ Magardchian A. Durability of reinforced concrete structures. Publishing Planning and Budget Organization
} 
In reinforced concrete structures, the treatment of beam-column links has a considerable result on the overall treatment of the structure. Thus, the science of the fracture mode in these components can be vital. The best procedures for maintaining concrete also can be beneficial instrumentations in structural engineering issues such as the initial research of destructions in available concrete structures or for retrofitting utilizations. Past investigation studies have been directed on the ductility of concrete elements reinforced with welded wire reinforcement and specified a recent occurrence called strain localization decreases element ductility owing to the higher bond between welded wire reinforcement and concrete. Such investigations have deduced that strain localization adversely impresses the ductility of elements reinforced with welded wire reinforcement and it is dangerous to apply welded wire reinforcement as tension reinforcement. Polymer concrete is a waterproof and chemical persistent concrete with considerable mechanical features. However, for most construction engineers, Polymer concrete beneficial does not exceed its higher value when contrasted with usual cement concrete. Corrosion is the main component in the failure of reinforced concrete constructions. To reduce this issue, steel bars can be subbed with glass-fiber-reinforced-polymer beams. but, the loss of ductility of glass-fiber-reinforced-polymer-reinforce concrete components has hindered their application in many constructions usages, mainly in seismic zones.

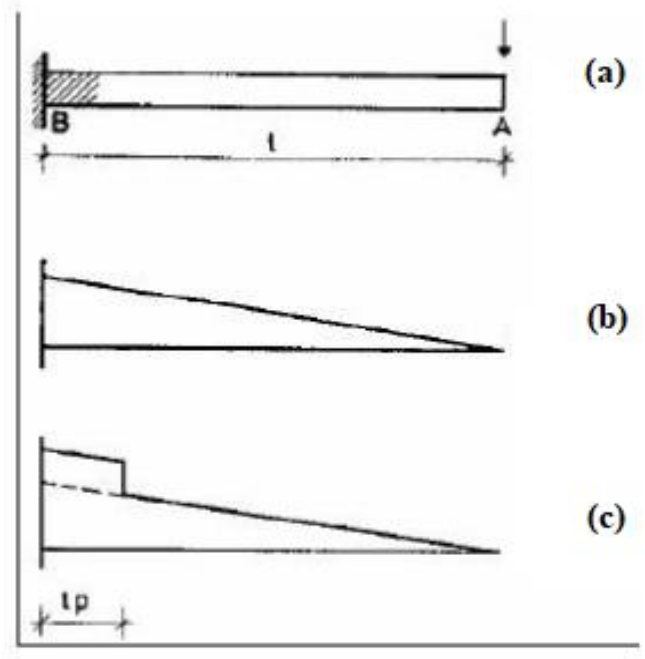

Fig2. The plot of variation along the beam (Hadian N, 1996).

\subsection{Variable and Alternative Stresses and Fatigue (Hadian N, 1996)}

Concrete foundation is affected by alternative and continuous wind-induced loads through the wire is affected by variable and alternative stresses. The results of experiment indicated that building materials under the influence of this loading shows earlier failure than static loading and the tensions much less than the interruption and sometimes less than reactionary will cause to failure of the material. Reducing the resistance under the influence of repetitious and alternative forces is called fatigue. Recently it has been proven that the structure of materials is not affected by alternative stresses and just they are weakened. Material under influence of these stresses is just a local phenomenon. it means that by formation the microscopic crack in concentration area of stress, the alternation of stresses causes to expand the surfaces of crack and slippage. The progressive deterioration becomes apparent after the certain number of alternative interruption cycles ${ }^{3}$. At this stage chemical agents especially water penetration and rusting of steel occurs. due to increase the intensity of alternative wind- induced loads, the bases in the two- wire lines show more progressive deterioration than single-circuit lines at the same conditions (Hadian N, 1996).

reuse rubber segments and steel fibers have the possible to increase the plasticity and ductility of concrete and generate more tolerable solutions. A purified engineering regulation for the evaluation of the surviving fatigued life of concrete under pressing cyclic loading with differing extents is suggested. The regulation has been obtained depend on a composed numerical and empirical research of the loading subsequence result. The practical modeling method depends on a loss model applying

\footnotetext{
${ }^{3}$ Magardchian A. Static calculations.

International Journal of Modern Studies in Mechanical Engineering (IJMSME)
} 
the similar tensile strain rate to control the fatigue damage progress upon loading at subcritical load areas. A recent corrosion fatigue life prognostication way for steel bar in concrete depends on fatigue fracture diffusion and equipollent initial flaw size was suggested, combine with corrosion development and fatigue fracture diffusion together. Fatigue loss is one of the most vital components affecting the chloride distribution factor in concrete. Fatigue damage in concrete is determined by the concurrent attendance of micro and macrocracks. The consequences are accredited applying present experiential information on concrete fatigue concluding hardness decadence and acoustic publication.

\subsection{Toughness (Hadian N, 1996)}

The toughness of concrete material is low because they cannot absorb too much energy without interruption. In other words, toughness is a property that results from the combination of two properties of well resistance and ductility (well resistance and bending) which indicates the ability to absorb shaking and shocking without break down in material. The brittle materials such as concrete are extremely low toughness because their plastic deformation is small before their interruption (Hadian N, 1996).

Fracture of concrete constructions is normally attended by the development of indoor fractures owing to stress condensation at the fractures tip. This occurrence displays the significance of consideration of the fracture treatment of concrete constructions. Low failure toughness of concrete shows a significant deficiency. An impressive procedure to update the concrete toughness is showed by the scattering of discontinuous fibers into the concrete combination. The achieved consequences are considered in the resolution of concrete constructions subjected to complex loading, or structures where the torsional moment is the basic load. A possible answer to maintenance fractures in concrete has been lately appointed, namely independent healing by embedding maintenance factor into concrete during casting. Most of the literature investigation concentrates on the relieve system plan and the repair efficiency evaluation. Mixture with the excess of coal fly ash can be included in the tolerable and green concrete. Impressive upgrade of green concrete combining coal fly ash is essential to reduce the danger to the environment caused by coal fly ash waste exposure and to decrease cement utilization thus cutting $\mathrm{CO} 2$ publications.

\subsection{Brittleness (Hadian N, 1996)}

Concrete is a brittle material and unlike plastic materials it can only withstand a very small deformation before breaking. But arranging the cross-section of concrete foundations in small size, reinforcing of them will lead to increase its ductility and gradual break down due to presence of steel. If the steel is used in cross- section to minimum value that determined by computational regulations the sudden break down in foundations will decrease. Before the failure due to crust of concrete membrane the steel announces its break down and later after some sections were crushed a new set of balance takes place due to ductility of steel and this leads to decrease the sudden failure with reversal. After investigating the stressors and effective factors in creation and spreading of failures we consider the bonding, neutral bonding and bonding breakage mechanism (Hadian N, 1996).

The usages of self-compacting concrete have lately been more usual in action. self-compressing concrete is an extremely flowable kind of concrete that deploys into the formwork itself without any automatic shake. In addition, failure features and brittleness of self-compacting concrete can be improved by usages of complementary cementitious material owing to concrete inner construction compression. In this investigation, experiential research on the failure components of self-pressing lightweight concrete applying tap and magnetic water is showed. For all self-pressing weightless concrete combination, usual failure components were determined by means of both work of failure procedure and the size result way. experiment consequences displayed that higher volume quantity of lightweight aggregate terminated in more brittle failure. It was also realized that for equivalent concrete stabilities, weightless aggregate concrete was relatively brittle than ordinary weight concrete. The acquired consequences showed that there is a considerable relationship between the water/cement proportion, failure treatment, and mechanical features of this material.

\subsection{Bonding}

The bonding breakage is different for simple and ribbed rebar. In simple rebar that are not restrained by the end hook the bonding strength is negligible and the bond failure is result of slide of rebar in 
concrete and after the slide the place remains in the form of hole in concrete ${ }^{4}$. contact pressure resistances are the main reason for tenacity and bonding that occurs between the edges of ribbed rebar and concrete (figure 3) (Hadian N, 1996). As a result of presence of contact stresses that have the vertical component the bonding breakage around the ribbed rebar happens in the form of splitting of concrete. the splitting mechanism of concrete around the rebar is shown in figure 4 . If the diameter of the rebar is low and the concentration of the concrete is excessive or when the air cavity is formed under the rebar located at the upper level, the ribbed rebar is pulled out completely from the hole due to bond failure. The bond strength is directly related to $\sqrt{f_{\mathrm{x}}}$ (tension resistance and concrete split) and has inverse relation to diameter of rebar. According to the studies the coating of concrete on the rebar, the distance between the rebar and the presence of stirrup are the most important factors in bonding or splitting resistance. If the rebar is located at the top of the organ due to formation of air cavities under the rebar due to subside and drop of fresh concrete during concrete and the solidification time the bonding resistance is low for the rebar (Hadian N, 1996).

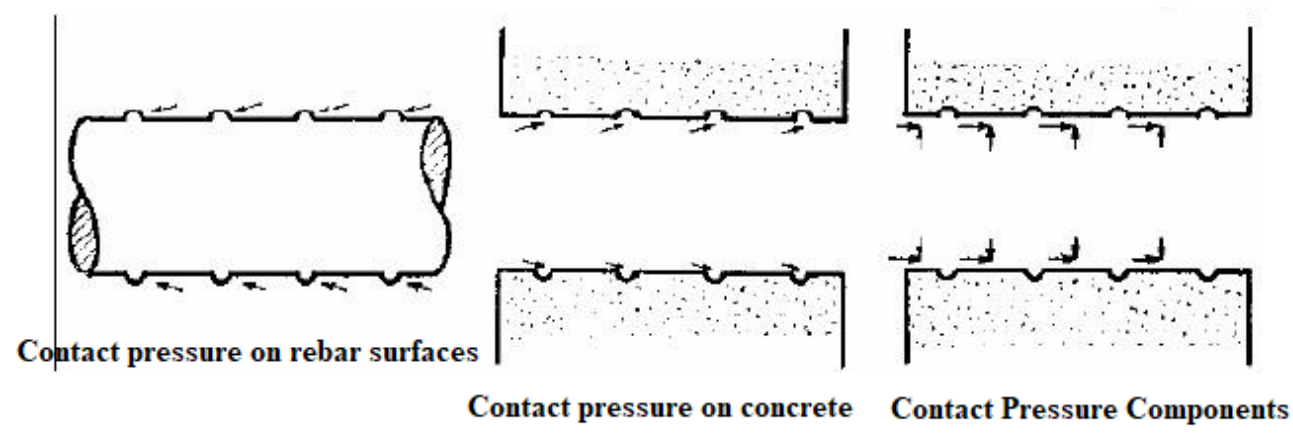

Fig3. Bonding that occurs between the edges of ribbed rebar and concrete (Hadian N, 1996).

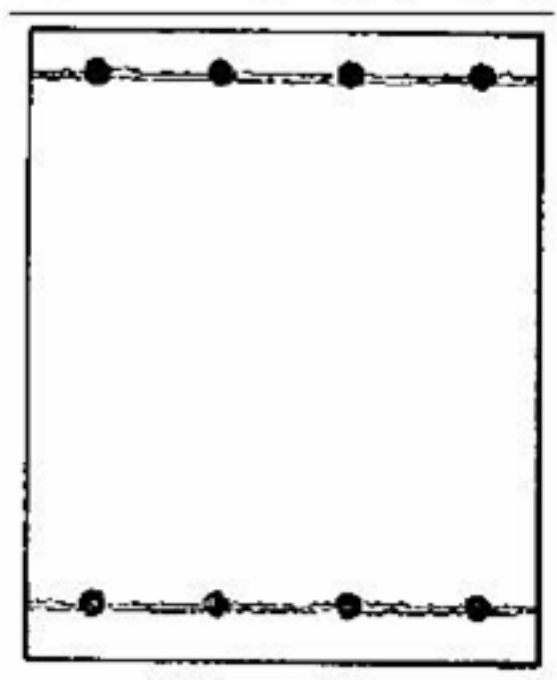

Fig4. Cracks caused by splitting concrete around the rebar (Hadian N, 1996).

Cracking in reinforced concrete constructions is of main disquiet since it may modify their permanence and construction totality. Cracking is mostly affected by stress dispensation along with the interface between steel and concrete which is accountable for transferring load from steel bar to the nearby matrix. Therefore, quantitative assessment of steel-concrete bond result on failure features is essential. It identifies some most significance components impressing the bond features between concrete and reinforcement within reinforced concrete beams at high temperatures. These components are steel bar yielding, concrete cover, concrete compressive strength and concrete spalling. The consequences showed that concrete cover has a considerable effect on the bond stability, by preparing the incarceration to the reinforcement for both the reinforced concrete beam and the slab. The effect of concrete spalling on the beam is very important, for both perfect bond and limited bond occasions.

\footnotetext{
${ }^{4}$ Tahouni Sh. Reinforced concrete.
} 
It was determined that under ambient situations as well as after disposal to high temperature, the concrete cover has a powerful effect on the total value of the bond stability and fracture mode. The thermal deterioration of bond stability is determined to be equivalent to that of the pressing or tensile stability of concrete for pure bond or splitting fracture respectively. The area of limitation prepared by the concrete cover to the rebar decreases with enhancing temperature when the width of splitting fractures enhances with enhancing temperature. The bond hardness regularly decreases with the enhance in exposure temperature for both relinquish and rupture fracture. Sufficient bonding between reinforcement and concrete performs an essential role in the appropriate efficiency of reinforced concrete as composite substances. Therefore, it is vital to assess the result of different components on the bond treatment of reinforcement and concrete. Longitudinal bond treatment between ribbed rebar and concrete is nearly connected to the cross-sectional limitation prepared by the concrete cover. Decadance of the bond between steel bars and concrete owing to erosion of steel notably impacts the permanence of reinforced concrete constructions. There are three procedures to transfer the interfacial shear (or bond) pressure between steel bars and concrete, i.e., adhesion, friction, and automatic interlock. A recent pattern for the bond-slip interconnection between steel bars and concrete concluding steel erosion component is suggested by improving a lately expanded unified bond-slip pattern. A logical procedure is applied in the modeling: the decadence of the bond is made by material decadence which can be shaped as depression of concrete stability, and the decadence of limitation is taken into account in the concrete cover result.

\section{SUGGESTIONS}

The corrosion phenomenon has been analyzed in concrete quadrangular foundations with mechanical view and the approaches to prevent of it are discussed (Hadian N, 1996). The experiment consequences displayed that the corrosion products motion through fractures impacts fracture dissemination. Steel erosion is an essential component in the strength of reinforced concrete parts. There are many investigations of reinforced concrete compression parts in erosive surroundings, but most investigation includes erosion under no load. The consequences display that the final bearing capacity of carious parts can be notably refined by applying epoxy-coated stirrups, mainly when the erosion degree is great. Under the same erosion grade, the final tolerance valency of the columns with stirrups built of usual steel bars enhances as the maintain load enhances, whereas, for the columns with stirrups built of epoxy-coated steel bars, the final tolerance valency reduces a little as the maintained load enhances.

1-2 in order to have the proper ductility, according to section 6 of the American concrete code (ACI), special projections are made for design of beam. These projections include the dimensions of steel, amount of longitudinal and latitudinal and inhibitory steel and so on. The most important points are (Hadian N, 1996) In reinforced concrete structures, the treatment of beam-column junctions has a considerable result on the overall treatment of the construction. Thus, understanding of the fracture mode in these components can be vital. They also can be beneficial instruments in construction engineering issues such as the primary research of destruction in available concrete constructions or for retrofitting usages:

-adjustment of tensional and compressive steel and cross- sectional dimensions so that the failure can be formulated and the percentage of tensional steel is less than the balanced steel and minimum and maximum must be monitor for ductility behavior (Hadian N, 1996).

-the need for using stirrups near to each other (up to 8 times the diameter of longitudinal rebar) in plastic area to keep the concrete core from surrounding and increasing its ductility at the pressure and supply the resting-place for compressive and longitudinal steel to prevent the non-elastic ricochet and common resistance between the concrete and steel against transverse shear force at crosssection(Hadian N, 1996).

2-2 by increasing coefficient in calculated loads or reducing factor in static stress fatigue can be compensated during analyzing and designing of bases (Hadian N, 1996).

3-2 use of stiff concrete and precision in vibration of concrete during construction of the bases to minimize the drop of concrete and reduce the formation of air cavities in the lower parts of the upper rebar and increase the adhesion between the concrete and rebar (Hadian N, 1996).

4-2 the lack of use of simple rebar in base construction due to low bonding and adhesion to concrete. this case will lead to decrease the consumption of steel in cross-section of beam (Hadian N, 1996).

International Journal of Modern Studies in Mechanical Engineering (IJMSME)

Page $\mid 36$ 
5-2 precision in arranging and adjusting the rebar in the mold during concrete and preventing the adhesion of rebar to the mold body and thereby maintaining the thickness of the concrete cover of the rebar (Hadian N, 1996).

6-2 avoid contamination of rebar with oil contaminated material (burned oil) that are worn on the interior surfaces of the mold (Hadian N, 1996).

Fig 5. Shows (a,b) plan of the revealed rebar zone (in mm), (c) model dimension (in mm), and (d) steel rebar situations in concrete models (D. V. Ribeiro, C. A. D. Rovere, et al.2011). Fig 6. Shows Device for quantifying the corrosion procedure by electrochemical resistivity spectroscopy (D. V. Ribeiro, C. A. D. Rovere, et al.2011).
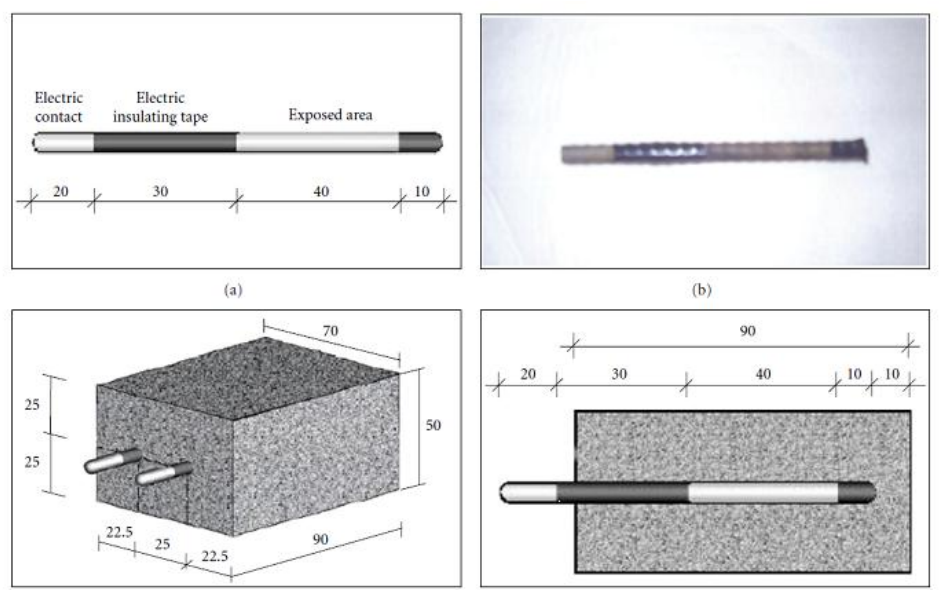

Fig5. $(a, b)$ plan of the revealed rebar zone (in $\mathrm{mm}$ ), (c) model dimension (in $\mathrm{mm}$ ), and (d) steel rebar situations in concrete models (D. V. Ribeiro, C. A. D. Rovere, et al.2011).

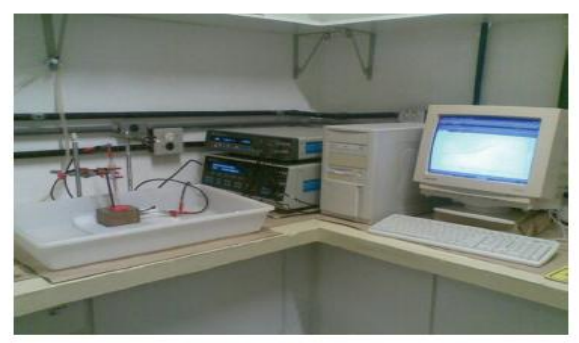

(a)

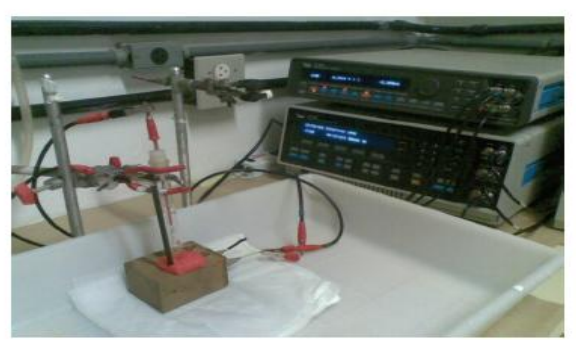

(b)

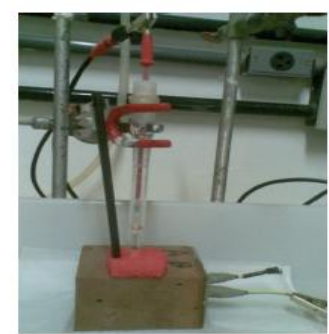

(c)

Fig6. Device for quantifying the corrosion procedure by electrochemical resistivity spectroscopy (D. V. Ribeiro, C. A. D. Rovere, et al.2011). 


\section{CONCLUSION}

In this paper the corrosion phenomenon in concrete quadrangular base investigated with mechanical and different view of previous papers and it has been shown that the initial factor for corrosion is a microscopic crack that occurs in maximum anchor region and the concentration point that stress appears in elementary parts of the foundation. The frequency of stress causes to increase and development of cracks and ultimately results in more intense and progressive deterioration with water penetration and rusting steel. Consideration and performing the mentioned points for coping with this phenomenon is one of the most important and determinant factor for increasing the network life longevity and durability and sustainability of them.

The products of steel erosion make volumetric development in the steel bars that detriment the concrete. The detriment of concrete by fracturing which generates an alteration of the tension dispensation overall part and causes an alteration of the bending stability and a decrease of the concrete-reinforcement bond owing to a loss of limitation is displayed. We can also examine the stability capacity of the reinforced concrete parts with rusty reinforcement exposed to bending under static load by straight and inverse procedures. Finally, It describes the construction results owing to erosion on components persistent to shear and torsion. Electrochemical procedures, concluding electrochemical impedance spectroscopy (EIS), are among the most usual procedures applied for the assessment and study of erosion in reinforced concrete. The amplitude debilitation procedure in ultrasonic testing was applied to assess the corrosion detriment of reinforced concrete parts. It is determined that the magnitude debilitation procedure has good efficiency in corrosion discovery for reinforced concrete parts.

\section{REFERENCES}

[1] Hadian N, 1996. A mechanical perspective of corrosion event in concrete quadrangular of power transition lines. Eleventh International Electrical Conference,Tehran. Mazandaran Power Consulting Co. Tavanir Co., Niroo Research Center.

[2] Magardchian A. Durability of reinforced concrete structures. Publishing Planning and Budget Organization

[3] Magardchian A. Static calculations.

[4] Tahouni Sh. Reinforced concrete.

[5] S Anders, M Alexander, et al. 2013. Concrete cover cracking due to uniform reinforcement corrosion. Materials and Structures. November 2013, Volume 46, Issue 11, pp 1781-1799.

[6] Michel, A. O. S. Solgaard, et al. 2013. Experimental investigation of the relation between damage at the concrete-steel interface and initiation of reinforcement corrosion in plain and fibre reinforced concrete. Corrosion Science, Volume 77, December 2013, Pages 308-321.

[7] Alexander Michel, Brad J. Pease,Et al. 2014. Penetration of corrosion products and corrosion-induced cracking in reinforced cementitious materials: Experimental investigations and numerical simulations. Cement and Concrete Composites, Volume 47, March 2014, Pages 75-86.

[8] E. Sola, J. Ožbolt, G. Balabanić, Z. M. Mir. 2019. Experimental and numerical study of accelerated corrosion of steel reinforcement in concrete: Transport of corrosion products. Cement and Concrete Research, Volume 120, June 2019, Pages 119-131.

[9] WeiboLiu, WenbingYu, et al. 2014. Thermal regime of frozen soil foundation affected by concrete base of transmission line tower on the Tibetan Plateau. Applied Thermal Engineering. Volume 75, 22 January 2015, Pages 950-957.

[10] B. Thapar, O. Ferrer, D.A. Blank. 1991. Ground resistance of concrete foundations in substation yards. Journals \& Magazines > IEEE Transactions on Power De... > Volume: 5 Issue: 1 .

[11] P.J.Murtagh, B.Basu, B.M.Broderick. 2005. Along-wind response of a wind turbine tower with blade coupling subjected to rotationally sampled wind loading. Engineering Structures. Volume 27, Issue 8, July 2005, Pages 1209-1219. https://doi.org/10.1016/j.engstruct.2005.03.004.

[12] W.H.MELBOURNE, J.C.K.CHEUNG. 1988. REDUCING THE WIND LOADING ON LARGE CANTILEVERED ROOFS. Advances in Wind Engineering. 1988, Pages 401-410. https://doi.org/ 10.1016/B978-0-444-87156-5.50051-5.

[13] Xiao Chen, Jing Tang, Ke Yang. 2019. Modeling multiple failures of composite box beams used in wind turbine blades. Composite Structures, Volume 217, 1 June 2019, Pages 130-142 
[14] Qiwei Xiong, Zhengnong Li, Haiyin Luo, Zhefei Zhao. 2019. Wind tunnel test study on wind load coefficients variation law of heliostat based on uniform design method. Solar Energy, Volume 184, 15 May 2019, Pages 209-229

[15] Léon Chiriatti, Hugo Mercado-Mendoza, Komla Lolonyo Apedo, Christophe Fond, Françoise Feugeas. 2019. A study of bond between steel rebar and concrete under a friction-based approach. Cement and Concrete Research, Volume 120, June 2019, Pages 132-141.

[16] QiweiXiong, ZhengnongLi ,HaiyinLuo ,ZhefeiZhao. 2019. Wind tunnel test study on wind load coefficients variation law of heliostat based on uniform design method. Solar Energy. Volume 184, 15 May 2019, Pages 209-229

[17] Sophia C. Alih, Mohammadreza Vafaei. 2019. Performance of reinforced concrete buildings and wooden structures during the $2015 \mathrm{Mw}$ 6.0 Sabah earthquake in Malaysia. Engineering Failure Analysis. Volume 102, August 2019, Pages 351-368.

[18] MagnusCurrie,, MohamedSaafi , ChristosTachtatzis ,FrancisQuail. 2015. Structural integrity monitoring of onshore wind turbine concrete foundations. Renewable Energy. Volume 83, November 2015, Pages 11311138. https://doi.org/10.1016/j.renene.2015.05.006.

[19] C. Monticelli, A. Balbo, J. Esvan, et al. 2019. Evaluation of 2-(salicylideneimino) thiophenol and other Schiff bases as bronze corrosion inhibitors by electrochemical techniques and surface analysis. Corrosion Science, Volume 148, March 2019, Pages 144-158.

[20] Shirin Shahabi, Sarmin Hamidi, Jahan B. Ghasemi, Parviz Norouzi, Alireza Shakeri. 2019. Synthesis, experimental, quantum chemical and molecular dynamics study of carbon steel corrosion inhibition effect of two Schiff basesin HCl solution. Journal of Molecular Liquids, Volume 285, 1 July 2019, Pages 626639.

[21] Serpil Şafak, Berrin Duran, Aysel Yurt, Gülşen Türkoğlu. 2012. Schiff bases as corrosion inhibitor for aluminium in $\mathrm{HCl}$ solution. Corrosion Science, Volume 54, January 2012, Pages 251-259.

[22] Priyanka Singh, M. A. Quraishi. 2016. Corrosion inhibition of mild steel using Novel Bis Schiff's Bases as corrosion inhibitors: Electrochemical and Surface measurement. Measurement, Volume 86, May 2016, Pages 114-124.

[23] U. J. Naik, P. C. Jha, M. Y. Lone, R. R. Shah, N. K. Shah. 2016. Electrochemical and theoretical investigation of the inhibitory effect of two Schiff bases of benzaldehyde for the corrosion of aluminium in hydrochloric acid. Journal of Molecular Structure, Volume 1125, 5 December 2016, Pages 63-72.

[24] Yijian Zhang, Reginald DesRoches, Iris Tien. 2019. Impact of corrosion on risk assessment of shearcritical and short lap-spliced bridges. Engineering Structures, Volume 189, 15 June 2019, Pages 260-271

[25] Wenting Yuan, Anxin Guo, Wei Yuan, Hui Li. 2018. Experimental investigation on cyclic behavior of coastal bridge piers with non-uniform corrosion under biaxial quasi-static loads. Construction and Building Materials, Volume 190, 30 November 2018, Pages 222-234

[26] Peng Deng, Chao Zhang, Shiling Pei, Zhibin Jin. 2018. Modeling the impact of corrosion on seismic performance of multi-span simply-supported bridges. Construction and Building Materials, Volume 185, 10 October 2018, Pages 193-205

[27] Wei Yuan, Anxin Guo, Wenting Yuan, Hui Li. 2018. Shaking table tests of coastal bridge piers with different levels of corrosion damage caused by chloride penetration. Construction and Building Materials, Volume 173, 10 June 2018, Pages 160-171

[28] M. Otieno, H. Beushausen, M. Alexander. 2016. Chloride-induced corrosion of steel in cracked concretePart II: Corrosion rate prediction models. Cement and Concrete Research, Volume 79, January 2016, Pages 386-394

[29] Michel, A. O. S. Solgaard, et al. 2013. Experimental investigation of the relation between damage at the concrete-steel interface and initiation of reinforcement corrosion in plain and fibre reinforced concrete. Corrosion Science, Volume 77, December 2013, Pages 308-321

[30] Qiang Li, Ke Li, Kang Zhao, Guangxu Sun, Sang Luo. 2019. Fuel oil corrosion resistance of asphalt mixtures. Construction and Building Materials, Volume 220, 30 September 2019, Pages 10-20

[31] Salvador Ivorra, Dora Foti, Valentina Gallo, Vitantonio Vacca, David Bru. 2019. Bell's dynamic interaction on a reinforced concrete bell tower. Engineering Structures, Volume 183, 15 March 2019, Pages 965-975.

[32] S. C. Seetharam, E. Laloy, et al. 2019. A mesoscale framework for analysis of corrosion induced damage of concrete. Construction and Building Materials, Volume 216, 20 August 2019, Pages 347-361.

[33] Hosein Naderpour, Masoomeh Mirrashid. 2019. Classification of failure modes in ductile and nonductile concrete joints. Engineering Failure Analysis, Volume 103, September 2019, Pages 361-375 
[34] Mohamed Shwani, Raed Tawadrous, Marc Maguire. 2019. Ductility of Concrete Members Reinforced with Welded Wire Reinforcement (WWR). Engineering Structures, Volume 191, 15 July 2019, Pages 711723

[35] AlaEddin Douba, Mehmet Emiroglu, Usama $\quad$ F. Kandil, Mahmoud M. Reda Taha. 2019. Very ductile polymer concrete using carbon nanotubes. Construction and Building Materials, Volume 196, 30 January 2019, Pages 468-477.

[36] M. A. Youssef, M. E. Meshaly, A. A. Elansary. 2019. Ductile corrosion-free selfcentering concrete elements. Engineering Structures, Volume 184, 1 April 2019, Pages 52-60

[37] Mulian Zheng,Peng Li, et al. 2019. Fatigue character comparison between high modulus asphalt concrete and matrix asphalt concrete. Construction and Building Materials, Volume 206, 10 May 2019, Pages 655-664

[38] Abdulaziz Alsaif, Reyes Garcia, et al. 2019. Fatigue performance of flexible steel fibre reinforced rubberised concrete pavements. Engineering Structures, Volume 193, 15 August 2019, Pages 170-183

[39] Zhiwen Zhu, Ze Xiang, Y. Edward Zhou. 2019. Fatigue behavior of orthotropic steel bridge stiffened with ultra-high performance concrete layer. Journal of Constructional Steel Research, Volume 157, June 2019, Pages 132-142

[40] Verônica Scarpini Cândido, Alisson Clay Rios da Silva, et al. Mechanical and microstructural characterization of geopolymeric concrete subjected to fatigue. Journal of Materials Research and Technology, Volume 7, Issue 4, October-December 2018, Pages 566-570

[41] Abedulgader Baktheer, Josef Hegger, Rostislav Chudoba. 2019. Enhanced assessment rule for concrete fatigue under compression considering the nonlinear effect of loading sequence. International Journal of Fatigue, Volume 126, September 2019, Pages 130-142

[42] Junzu Sun, Zhiheng Ding, Qiao Huang. 2019. Corrosion fatigue life prediction for steel bar in concrete based on fatigue crack propagation and equivalent initial flaw size. Construction and Building Materials, Volume 195, 20 January 2019, Pages 208-217

[43] Linhua Jiang, Chenzhi Li, Chenglong Zhu, Zijian Song, Hongqiang Chu. 2017. The effect of tensile fatigue on chloride ion diffusion in concrete. Construction and Building Materials, Volume 151, 1 October 2017, Pages 119-126

[44] Mohammadali Rezazadeh, Valter Carvelli. 2018. A damage model for high-cycle fatigue behavior of bond between FRP bar and concrete. International Journal of Fatigue, Volume 111, June 2018, Pages 101-111

[45] K. M. Pervaiz Fathima, J. M. Chandra Kishen. 2015. A thermodynamic correlation between damage and fracture as applied to concrete fatigue. Engineering Fracture Mechanics, Volume 146, September 2015, Pages 1-20

[46] Yougui Lin, John N. Karadelis. 2019. Interfacial fracture toughness of composite concrete beams. Construction and Building Materials, Volume 213, 20 July 2019, Pages 413-423

[47] Wei Hou, Shilang Xu, Dashuai Ji, Qinghua Li, Pan Zhang. 2019. Seismic performance of steel plate reinforced high toughness concrete coupling beams with different steel plate ratios. Composites Part B: Engineering, Volume 159, 15 February 2019, Pages 199-210

[48] Amin Nazerigivi, Hamid Reza Nejati, Abdolhadi Ghazvinian, Alireza Najigivi.2018. Effects of SiO2 nanoparticles dispersion on concrete fracture toughness. Construction and Building Materials, Volume 171, 20 May 2018, Pages 672-679

[49] Andrea Carpinteri, Giovanni Fortese, Camilla Ronchei, Daniela Scorza, Sabrina Vantadori. 2017. Mode I fracture toughness of fibre reinforced concrete. Theoretical and Applied Fracture Mechanics, Volume 91, October 2017, Pages 66-75.

[50] Soner Guler. 2018. The effect of polyamide fibers on the strength and toughness properties of structural lightweight aggregate concrete. Construction and Building Materials, Volume 173, 10 June 2018, Pages 394-402

[51] Grzegorz Ludwik Golewski. 2019. Estimation of the optimum content of fly ash in concrete composite based on the analysis of fracture toughness tests using various measuring systems. Construction and Building Materials, Volume 213, 20 July 2019, Pages 142-155

[52] Zhihong Wang, Zheming Zhu, Xin Sun, Xiaomeng Wang. 2017. Deterioration of fracture toughness of concrete under acid rain environment. Engineering Failure Analysis, Volume 77, July 2017, Pages 76-84

[53] Grzegorz Ludwik Golewski. 2018. Effect of curing time on the fracture toughness of fly ash concrete composites. Composite Structures, Volume 185, 1 February 2018, Pages 105-112

International Journal of Modern Studies in Mechanical Engineering (IJMSME)

Page | 40 
[54] Yanhua Zhao, Wei Dong, Bohan Xu, Jin Liu.2018. Effect of T-stress on the initial fracture toughness of concrete under I/II mixed-mode loading. Theoretical and Applied Fracture Mechanics, Volume 96, August 2018, Pages 699-706

[55] F. Kazemian, H. Rooholamini, A. Hassani. 2019. Mechanical and fracture properties of concrete containing treated and untreated recycled concrete aggregates. Construction and Building Materials, Volume 209, 10 June 2019, Pages 690-700

[56] Eleni Tsangouri, Francisco A. Gilabert, et al. Concrete fracture toughness increase by embedding selfhealing capsules using an integrated experimental approach. Construction and Building Materials, Volume 218, 10 September 2019, Pages 424-433

[57] Ahmed Tareq Noaman, B. H. Abu Bakar, Hazizan Md. Akil. 2016. Experimental investigation on compression toughness of rubberized steel fibre concrete. Construction and Building Materials, Volume 115, 15 July 2016, Pages 163-170

[58] Ahmad Mansourian, Shabnam Hashemi, Mohammad Reza Mohammad Aliha. 2018. Evaluation of pure and mixed modes (I/III) fracture toughness of Portland cement concrete mixtures containing reclaimed asphalt pavement. Construction and Building Materials, Volume 178, 30 July 2018, Pages 10-18

[59] Changlin Zhou, Zheming Zhu, Zhihong Wang, Hao Qiu. 2018. Deterioration of concrete fracture toughness and elastic modulus under simulated acid-sulfate environment. Construction and Building Materials, Volume 176, 10 July 2018, Pages 490-499

[60] Janusz Konkol, Grzegorz Prokopski. 2016. Fracture toughness and fracture surfaces morphology of metakaolinite-modified concrete. Construction and Building Materials, Volume 123, 1 October 2016, Pages 638-648

[61] Jisun Choi, Goangseup Zi, Shinichi Hino, Kohei Yamaguchi, Soye Kim. 2014. Influence of fiber reinforcement on strength and toughness of all-lightweight concrete. Construction and Building Materials, Volume 69, 30 October 2014, Pages 381-389

[62] Minglei Zhao, Mingshuang Zhao, Meihua Chen, Jie Li, David Law. 2018. An experimental study on strength and toughness of steel fiber reinforced expanded-shale lightweight concrete. Construction and Building Materials, Volume 183, 20 September 2018, Pages 493-501

[63] Grzegorz Ludwik Golewski. 2017. Improvement of fracture toughness of green concrete as a result of addition of coal fly ash. Characterization of fly ash microstructure. Materials Characterization, Volume 134, December 2017, Pages 335-346

[64] Longbang Qing, Yuehua Cheng. 2018. The fracture extreme theory for determining the effective fracture toughness and tensile strength of concrete. Theoretical and Applied Fracture Mechanics, Volume 96, August 2018, Pages 461-467

[65] Elias Molaei Raisi, Javad Vaseghi Amiri, Mohammad Reza Davoodi.2018. Influence of rice husk ash on the fracture characteristics and brittleness of self-compacting concrete. Engineering Fracture Mechanics, Volume 199, August 2018, Pages 595-608

[66] Alain Sellier, Alain Millard. 2019. A homogenized formulation to account for sliding of non-meshed reinforcements during the cracking of brittle matrix composites: Application to reinforced concrete. Engineering Fracture Mechanics, Volume 213, 15 May 2019, Pages 182-196.

[67] Iman M. Nikbin, Maryam Golshekan. 2018. The effect of expanded polystyrene synthetic particles on the fracture parameters, brittleness and mechanical properties of concrete. Theoretical and Applied Fracture Mechanics, Volume 94, April 2018, Pages 160-172.

[68] Andrey P. Jivkov, Dirk L. Engelberg, Robert Stein, Mihail Petkovski. 2013. Pore space and brittle damage evolution in concrete. Engineering Fracture Mechanics, Volume 110, September 2013, Pages 378-395

[69] Zhengyang Song, Heinz Konietzky, Thomas Frühwirt. 2018. Hysteresis energy-based failure indicators for concrete and brittle rocks under the condition of fatigue loading. International Journal of Fatigue, Volume 114, September 2018, Pages 298-310

[70] Hasan Salehi, Moosa Mazloom. 2019. An experimental investigation on fracture parameters and brittleness of self-compacting lightweight concrete containing magnetic field treated water. Archives of Civil and Mechanical Engineering, Volume 19, Issue 3, May 2019, Pages 803-819

[71] H. Z. Cui, Tommy Yiu Lo, Shazim Ali Memon, Weiting Xu. 2012. Effect of lightweight aggregates on the mechanical properties and brittleness of lightweight aggregate concrete. Construction and Building Materials, Volume 35, October 2012, Pages 149-158

[72] Mohammad Karamloo, Moosa Mazloom, Golamhasan Payganeh. 2016. Influences of water to cement ratio on brittleness and fracture parameters of self-compacting lightweight concrete. Engineering Fracture Mechanics, Volume 168, Part A, December 2016, Pages 227-241 
[73] Morteza H. A. Beygi, Mohammad T. Kazemi, Iman M. Nikbin, Javad. Vaseghi Amiri. 2013. The effect of water to cement ratio on fracture parameters and brittleness of self-compacting concrete. Materials \& Design, Volume 50, September 2013, Pages 267-276

[74] Cristina Zanotti, Norbert Randl. 2019. Are concrete-concrete bond tests comparable? Cement and Concrete Composites, Volume 99, May 2019, Pages 80-88. Cristina Zanotti, Norbert Randl

[75] F. Ascione, M. Lamberti, A. Napoli, A. G. Razaqpur, R. Realfonzo. 2019. Modeling SRPconcrete interfacial bond behavior and strength. Engineering Structures, Volume 187, 15 May 2019, Pages 220-230

[76] Michele Win Tai Mak, Pieter Desnerck, Janet M. Lees. 2019. Corrosion-induced cracking and bond strength in reinforced concrete. Construction and Building Materials, Volume 208, 30 May 2019, Pages 228-241

[77] Jacqueline Saliba, Djillali Mezhoud. 2019. Monitoring of steel-concrete bond with the acoustic emission technique. Theoretical and Applied Fracture Mechanics, Volume 100, April 2019, Pages 416-425

[78] Jamal Khalaf, Zhaohui Huang. 2019. The bond behaviour of reinforced concrete members at elevated temperatures. Fire Safety Journal, Volume 103, January 2019, Pages 19-33

[79] Akanshu Sharma, Josipa Bošnjak, Saskia Bessert. 2019. Experimental investigations on residual bond performance in concrete subjected to elevated temperature. Engineering Structures, Volume 187, 15 May 2019, Pages 384-395

[80] Rajai Z. Al-Rousan, Mohammad F. AL-Tahat. 2019. Consequence of surface preparation techniques on the bond behavior between concrete and CFRP composites. Construction and Building Materials, Volume 212, 10 July 2019, Pages 362-374

[81] Jia-Bao Yan, Wenjun Xie, Lingxin Zhang, Xu-Chuan Lin. 2019. Bond behaviour of concrete-filled steel tubes at the Arctic low temperatures. Construction and Building Materials, Volume 210, 20 June 2019, Pages 118-131

[82] Yanjun Shen, Yongzhi Wang, Et al. 2019. Influence of surface roughness and hydrophilicity on bonding strength of concrete-rock interface. Construction and Building Materials, Volume 213, 20 July 2019, Pages 156-166

[83] Musab Alhawat, Ashraf Ashour. 2019. Bond strength between corroded steel reinforcement and recycled aggregate concrete. Structures, Volume 19, June 2019, Pages 369-385.

[84] Z. H. Mohebi, A. B. Bahnamiri, M. Dehestani. 2019. Effect of polypropylene fibers on bond performance of reinforcing bars in high strength concrete. Construction and Building Materials, Volume 215, 10 August 2019, Pages 401-409

[85] Léon Chiriatti, Hugo Mercado-Mendoza, Komla Lolonyo Apedo, Christophe Fond, Françoise Feugeas. 2019. A study of bond between steel rebar and concrete under a friction-based approach. Cement and Concrete Research, Volume 120, June 2019, Pages 132-141

[86] Cheng Jiang, Yu-Fei Wu, Ming-Jiang Dai. 2018. Degradation of steel-to-concrete bond due to corrosion. Construction and Building Materials, Volume 158, 15 January 2018, Pages 1073-1080

[87] Zahra Amalia,Di Qiao, Hikaru Nakamura, Taito Miura, Yoshihito Yamamoto. 2018. Development of simulation method of concrete cracking behavior and corrosion products movement due to rebar corrosion. Construction and Building Materials, Volume 190, 30 November 2018, Pages 560-572

[88] C. Grengg, F. Mittermayr, et al. 2017. The decisive role of acidophilic bacteria in concrete sewer networks: A new model for fast progressing microbial concrete corrosion. Cement and Concrete Research, Volume 101, November 2017, Pages 93-101

[89] Dawang Li, Ren Wei, L. Li, Xiaotao Guan, Xuming Mi. 2019. Pitting corrosion of reinforcing steel bars in chloride contaminated concrete. Construction and Building Materials, Volume 199, 28 February 2019, Pages 359-368

[90] Dif Fodil, Mouli Mohamed. 2018. Compressive strength and corrosion evaluation of concretes containing pozzolana and perlite immersed in aggressive environments. Construction and Building Materials, Volume 179, 10 August 2018, Pages 25-34

[91] Xun Wu, Lei Chen, Hui Li, Jun Xu. 2019. Experimental study of the mechanical properties of reinforced concrete compression members under the combined action of sustained load and corrosion. Construction and Building Materials, Volume 202, 30 March 2019, Pages 11-22

[92] Cyrill Grengg, Florian Mittermayr, et al. Advances in concrete materials for sewer systems affected by microbial induced concrete corrosion: A review. Water Research, Volume 134, 1 May 2018, Pages 341-352

[93] Shuxian Hong, Herbert Wiggenhauser, etal. 2017. Long-term monitoring of reinforcement corrosion in concrete using ground penetrating radar. Corrosion Science, Volume 114, January 2017, Pages 123-132.

International Journal of Modern Studies in Mechanical Engineering (IJMSME)

Page $\mid 42$ 
[94] Andrielli Morais de Oliveira, Oswaldo Cascudo, 2018. Effect of mineral additions incorporated in concrete on thermodynamic and kinetic parameters of chloride-induced reinforcement corrosion. Construction and Building Materials, Volume 192, 20 December 2018, Pages 467-477

[95] Hamid Eskandari-Naddaf, Ali Ziaei-Nia. Simultaneous effect of nano and micro silica on corrosion behaviour of reinforcement in concrete containing cement strength grade of C-525. Procedia Manufacturing, Volume 22, 2018, Pages 399-405

[96] Hosein Naderpour, Masoomeh Mirrashid. 2019. Classification of failure modes in ductile and nonductile concrete joints. Engineering Failure Analysis, Volume 103, September 2019, Pages 361-375

[97] Mohamed Shwani, Raed Tawadrous, Marc Maguire. 2019. Ductility of Concrete Members Reinforced with Welded Wire Reinforcement (WWR). Engineering Structures, Volume 191, 15 July 2019, Pages 711723

[98] Roberto Capozucca. 1995. Damage to reinforced concrete due to reinforcement corrosion. Construction and Building Materials. Volume 9, Issue 5, October 1995, Pages 295-303. https://doi.org/10.1016/09500618(95)00033-C.

[99] W.Yeih R.Huang.. 1998. Detection of the corrosion damage in reinforced concrete members by ultrasonic testing. Cement and Concrete Research. Volume 28, Issue 7, July 1998, Pages 1071-1083. https://doi.org/10.1016/S0008-8846(98)00060-X

[100]D. V. Ribeiro, C. A. D. Rovere, C. A. C. Souza,1 S. E. Kuri, J. A. Labrincha, J. C. C. Abrantes, andM. R.Morelli. 2011. Effect of RedMud on the Corrosion of Reinforced. Concrete Studied by Electrochemical Impedance Spectroscopy. International Scholarly Research Network. ISRN Materials Science. Volume 2011, Article ID 365276, 11 pages. doi:10.5402/2011/365276.

Citation: Moein Zargar, et.al, (2019)" Mechanical View of Corrosion Phenomenon in Concrete Quadrangular of Power Transmission Lines", International Journal of Modern Studies in Mechanical Engineering, 5(2), pp. 30-43. DOI: http://dx.doi. org/10.20431/2454-9711.0502004

Copyright: () 2019 Authors, This is an open-access article distributed under the terms of the Creative Commons Attribution License, which permits unrestricted use, distribution, and reproduction in any medium, provided the original author and source are credited. 